\title{
Longevity of ground magnesium limestone applied to an Ultisol
}

\begin{abstract}
Soils in the upland areas of Malaysia are mostly weathered (Ultisols and Oxisols), having high aluminum $(\mathrm{Al})$, but calcium $(\mathrm{Ca})$ and/or magnesium $(\mathrm{Mg})$ deficient. Magnesium limestone is available in large quantities in Malaysia and is frequently being used to alleviate acidity in the upland soils. This study aimed at assessing the longevity of the limestone applied to an highly weathered acid soil under conditions prevailing in the tropics. The experiment consisted of two phases; in the first phase the plots were treated with various rates of lime, while in the second phase some plots were left as residual treatments. The results of the study showed that an acid Ultisol of Malaysia can be ameliorated by annual limestone application of $1 \mathrm{t}$ ha-1 for maize (Zea mays L.) production. The beneficial effects of liming with ground magnesium limestone (GML) at $4 \mathrm{t}$ ha-1 were observed for about eight years. The critical soil $\mathrm{pH}$ and exchangeable $\mathrm{Al}$ for maize production were found to be 5 and 0.7 cmol(c)kg-1 soil, respectively. The $\mathrm{Ca}$ and $\mathrm{Mg}$ from the limestone were mostly found in the topsoils because of the increase in cation exchange capacity (CEC) resulting from the $\mathrm{pH}$ increase.
\end{abstract}

Keyword: Magnesium; Limestone; Longevity; Acid soil 